\title{
Chemical immobilisation of the wild Patagonian otter (Lontra provocax) and the North American mink (Neovison vison)
}

\author{
Macarena Barros-Lama, Claudio Azat, Rodolfo Tardone, Gonzalo Medina-Vogel*
}

\begin{abstract}
The Patagonian otter (Lontra provocax) is an endangered species endemic to southern Chile and Argentina. Most of its distribution range has recently been occupied by the American mink (Neovison vison). As part of a long-term study on the impact of mink in Patagonia, we assessed five reversible anaesthetic combination protocols in different doses on wild L. provocax and N. vison, and described the occurrence of any adverse effects. We assessed 16 anaesthetic procedures with a combination of ketamine-medetomidine (KET-MED; 6.0 $\pm 2.8-0.05 \pm 0.01 \mathrm{mg} / \mathrm{kg}$ IM, respectively) or ketamine-dexmedetomidine (KET-DEX; 4.1 $\pm 0.9-0.02 \pm 0.004 \mathrm{mg} / \mathrm{kg} \mathrm{IM}$ ) in L. provocax and 23 anaesthetic procedures with KET-MED (13.3 $\pm 4-0.1 \pm 0.04 \mathrm{mg} / \mathrm{kg} \mathrm{IM}), \mathrm{KET}-\mathrm{DEX}(4.8 \pm 0.3-0.024 \pm 0.001 \mathrm{mg} / \mathrm{kg}$ IM) in a low dose of ketamine (LDK) or KET-DEX $(10.2 \pm 0.9-0.025 \pm 0.002 \mathrm{mg} / \mathrm{kg} \mathrm{IM})$ in a high dose of ketamine (HDK) in N. vison. Reversal was accomplished using atipamezole at 5 times the dose of MED or 10 times the dose of DEX. All anaesthetic combinations produced complete immobilisation and rapid anaesthetic induction, except for two otters anaesthetised with KET-MED which exhibited a longer time to initial effect. Hypothermia was commonly observed at the end of the anaesthetic procedures. Due to the hypoxemia presented in four otters at the beginning of anaesthesia, it is recommended to use additional oxygen when possible.

Key words: Anaesthesia, atipamezole, mustelid, reversal.
\end{abstract}

\section{INTRODUCTION}

The Patagonian otter (Lontra provocax) is an endangered species native to Southern Chile and Argentina (Larivière 1999) and the American mink (Neovison vison) an invasive species in Chile since the 1960s (Medina 1997). Recently undertaken research involving the capture of these two species has required anaesthesia (Soto-Azat et al 2006).

Ketamine (KET) combined with medetomidine (MED) followed by antagonism with atipamezole (ATI) is a welldocumented safe and efficient anaesthetic protocol to be used in carnivores (Jalanka and Roeken 1990), including mustelids, and recommended especially under field conditions (Spelman et al 1994, Spelman 1999). However, bradycardia, hypotension, hypoxemia and hypothermia have been described as major adverse effects (Spelman 1999, Fernandez-Moran et al 2001, Soto-Azat et al 2006). This study aimed to evaluate five anaesthetic combination protocols based on different doses of 3 drugs on wild $L$. provocax and N. vison, using KET-MED and KET-DEX, both antagonised with ATI, and to describe the main adverse effects observed.

\section{MATERIAL AND METHODS}

A total of 14 L. provocax and $23 N$. vison were captured in southern Chile between 2004 and 2013 (permit granted by Subsecretaria de Pesca No2286 and 448). Otters were

Received: 11.03.2020.

Accepted: 20.10.2020.

Centro de Investigación para la Sustentabilidad (CIS), Facultad de Ciencias de la vida, Universidad Andres Bello, Santiago, Chile.

*Corresponding author: gmedina@unab.cl captured with soft-catch leghold traps, and minks with box traps. After estimating the weight of each animal, they were physically restrained and injected with the anaesthetic combination administered by hand with a $1 \mathrm{ml}$ syringe and a $23 \mathrm{G}$ needle (Soto-Azat et al 2006). Anaesthetic protocols were divided into five groups: 1) four otters anaesthetised with a combination of KET-MED at a dose of 6.0 \pm 2.8 $0.05 \pm 0.01 \mathrm{mg} / \mathrm{kg}$ IM (two otters were anaesthetised twice; capture and subsequent radiotransmitter implantation), 2) 10 otters anaesthetised with a combination of KET-DEX at a dose of 4.1 $\pm 0.9-0.02 \pm 0.004 \mathrm{mg} / \mathrm{kg} \mathrm{IM}, 3) 10 \mathrm{minks}$ anaesthetised with a combination of KET-MED at a dose of $13.3 \pm 4-0.1 \pm 0.04 \mathrm{mg} / \mathrm{kg} \mathrm{IM}, 4)$ six minks anaesthetised with a combination of KET-DEX at a dose of 4.8 \pm 0.3 $0.024 \pm 0.001 \mathrm{mg} / \mathrm{kg}$ IM (low dose of ketamine: LDK), and 5) seven minks anaesthetised with a combination of KET-DEX at a dose of 10.2 $\pm 0.9-0.025 \pm 0.002 \mathrm{mg} / \mathrm{kg}$ IM (high dose of ketamine: HDK). Reversal was accomplished using ATI at five times the dose of MED or 10 times the dose of DEX, respectively. Details of anaesthetised individuals are provided in tables 1 and 2 .

Anaesthetic variables were recorded, including time to initial effect, recumbency time, loss of pedal reflex and reversal time. To evaluate the anaesthetic depth, we examined animals for sonorous stimulus response, jaw relaxation, interdigital toe pinch and level of alertness. The degree of muscular relaxation was characterised as "adequate" or "inadequate". Physiological parameters monitored were rectal temperature measured with a digital thermometer, cardiac rate measured with a stethoscope, respiratory rate, capillary refill time and arterial haemoglobin oxygen saturation $\left(\mathrm{SPO}_{2}\right)$ measured with a pulse oximeter, however, in the combination of KETDEX with LDK in minks it was not possible to measure $\mathrm{SPO}_{2}$. All parameters were monitored at $5 \mathrm{~min}$ intervals for $30 \mathrm{~min}$, following Soto-Azat et al (2006). 
Table 1. Summary of chemical immobilisation in wild otters (9 females and 5 males) anaesthetised intramuscularly with ketaminemedetomidine or ketamine-dexmedetomidine and reversed with atipamezole.

\begin{tabular}{lcccc}
\hline Parameters with KET-MED & $\mathrm{n}$ & Mean & SD & Range \\
\hline Weight $(\mathrm{kg})$ & 4 & 11.5 & 2.04 & $10-14.5$ \\
Ketamine dose (mg/kg) & 6 & 6.0 & 2.8 & $3.4-10.0$ \\
Medetomidine dose (mg/kg) & 6 & 0.05 & 0.01 & $0.03-0.06$ \\
Initial effect (min) & 6 & 4.9 & 4.3 & $1.2-10$ \\
Recumbency (min) & 6 & 5.7 & 3.08 & $2.4-10$ \\
Reversal times (min) & 6 & 18 & 12.5 & $5-37$ \\
Body temperature & 6 & 37.3 & 0.7 & $35.8-40$ \\
Heart rate & 6 & 86.1 & 9.1 & $73-93.2$ \\
Respiratory rate & 6 & 22.3 & 3.3 & $17.5-25.6$ \\
SpO & 3 & 86 & 7.21 & $80-94$ \\
\hline Parameters with KET-DEX & $\mathrm{n}$ & Mean & $\mathrm{SD}$ & Range \\
\hline Weight (kg) & 10 & 6.3 & 2.12 & $3-8.74$ \\
Ketamine dose (mg/kg) & 10 & 4.1 & 0.9 & $2.9-5.7$ \\
Dexmedetomidine dose (mg/kg) & 10 & 0.02 & 0.004 & $0.01-0.03$ \\
Initial effect (min) & 10 & 2.8 & 1.3 & $1.4-5.5$ \\
Recumbency (min) & 10 & 5.9 & 3.4 & $2.4-13$ \\
Reversal times (min) & 10 & 65.4 & 58.4 & $8-180$ \\
Body temperature & 10 & 37.1 & 0.7 & $32.2-39.1$ \\
Heart rate & 10 & 107.3 & 22 & $84-161$ \\
Respiratory rate & 10 & 38 & 16 & $23.3-52.66$ \\
SpO & 3 & 84.2 & 4.3 & $70-96$ \\
\hline
\end{tabular}

\section{RESULTS AND DISCUSSION}

The anaesthetic induction was rapid and smooth for all individuals, except for two otters anaesthetised with KETMED which exhibited a longer time to initial effect (10 min), however, this was shorter than the time reported by Bauquier et al (2010). The average time to initial effect for otters was 4.9 and $2.8 \mathrm{~min}$ for KET-MED and KET-DEX, respectively. The recumbency time was similar for both combinations. The average time to initial effect for minks was 1.7, 2.2 and $1.3 \mathrm{~min}$ for KET-MED, LDK KET-DEX and HDK KET-DEX, respectively. The recumbency time for minks was 6.2 min with LDK KET-DEX (table 2). The anaesthetic recovery following ATI administration was smooth and calm, as previously reported in other species of otters (Fernandez-Moran et al 2001, Soto-Azat et al 2006). The average time to total recovery in otters was 18.0 and $65.4 \mathrm{~min}$ for KET-MED and KET-DEX, respectively. In three otters anaesthetised with KET-DEX recovery lasted longer than 1 hour. The recovery in minks was evaluated only with the combination KET-DEX. Average total recovery time was 22.1 and 28.0 min with
LDK and HDK, respectively (these animals were released for home range studies). The other minks were euthanised following legal recommendations.

Muscle relaxation was classified as adequate for both anaesthetic protocols and both species. Capillary refill time in all cases fell within normal ranges (1-3 seconds).

For the KET-MED combination, the rectal temperature average was 37.3 and $37.4{ }^{\circ} \mathrm{C}$ in otters and minks, respectively. Temperature continuously decreased in all studied individuals. Further, four animals showed moderate hypothermia $\left(34-36{ }^{\circ} \mathrm{C}\right)$ at the end of the anaesthetic procedure. Rectal temperature also decreased in all individuals anaesthetised with the KET-DEX combination. The most affected were minks with HDK, decreasing to $35.3^{\circ} \mathrm{C}$ average (figure 1). Rectal temperature average in otters under KET-DEX was $37.1^{\circ} \mathrm{C}$. In minks with LDK the average was $36.7^{\circ} \mathrm{C}$ and in minks with HDK it was $35.4^{\circ} \mathrm{C}$ (figure 1). Anaesthetic related hypothermia usually occurs due to depression of the hypothalamic thermoregulatory centre, and as core body heat redistributes to the skin surface through anaesthetic-induced vasodilation (Matsukawa et al 1995, Taguchi and Kurz 2005). Although we tried 
Table 2. Summary of chemical immobilisation in minks (10 females and 13 males) anaesthetised intramuscularly with ketaminemedetomidine or ketamine-dexmedetomidine and reversed with atipamezole.

\begin{tabular}{|c|c|c|c|c|}
\hline Parameters with KET-MED & $\mathrm{n}$ & Mean & SD & Range \\
\hline Weight (kg) & 10 & 0.740 & 0.2 & $0.4-1.1$ \\
\hline Ketamine dose (mg/kg) & 10 & 13.3 & 4 & $9.1-20$ \\
\hline Medetomidine dose $(\mathrm{mg} / \mathrm{kg})$ & 10 & 0.1 & 0.04 & $0.09-0.2$ \\
\hline Initial effect (min) & 10 & 1.7 & 0.8 & $1-3.3$ \\
\hline Recumbency (min) & 8 & 3.3 & 2.1 & $1.3-7.4$ \\
\hline Reversal times (min) & - & - & - & - \\
\hline Body temperature & 10 & 37.4 & 0.7 & $34.1-39.7$ \\
\hline Heart rate & 10 & 130 & 4 & $80-196$ \\
\hline Respiratory rate & 10 & 39.5 & 6 & $24-83$ \\
\hline $\mathrm{SpO}_{2}$ & 9 & 93 & 1.2 & $80-100$ \\
\hline Parameters with KET-DEX (LDK) & $\mathrm{n}$ & Mean & SD & Range \\
\hline Weight (kg) & 6 & 0.560 & 0.2 & $0.375-1$ \\
\hline Ketamine dose (mg/kg) & 6 & 4.8 & 0.3 & $4.2-5$ \\
\hline Dexmedetomidine dose $(\mathrm{mg} / \mathrm{kg})$ & 6 & 0.024 & 0.001 & $0.021-0.025$ \\
\hline Initial effect (min) & 6 & 2.21 & 1.1 & $1-4$ \\
\hline Recumbency (min) & 6 & 6.2 & 4.6 & $2-13.3$ \\
\hline Reversal times (min) & 6 & 22.1 & 20 & $2.3-60$ \\
\hline Body temperature & 6 & 36.7 & 1.13 & $32.5-40.4$ \\
\hline Heart rate & 6 & 149 & 13 & $120-196$ \\
\hline Respiratory rate & 6 & 50 & 6.2 & $32-80$ \\
\hline $\mathrm{SpO}_{2}$ & - & - & - & - \\
\hline Parameters with KET-DEX (HDK) & $\mathrm{n}$ & Mean & SD & Range \\
\hline Weight (kg) & 7 & 0.635 & 0.2 & $0.380-1$ \\
\hline Ketamine dose (mg/kg) & 7 & 10.2 & 0.9 & $8.5-11$ \\
\hline Dexmedetomidine dose (mg/kg) & 7 & 0.025 & 0.002 & $0.021-0.028$ \\
\hline Initial effect (min) & 7 & 1.32 & 0.47 & $1-2$ \\
\hline Recumbency (min) & 7 & 2.85 & 0.69 & $2-4$ \\
\hline Reversal times (min) & 7 & 28 & 24.2 & $1.5-60$ \\
\hline Body temperature & 7 & 35.4 & 1.2 & $32-39$ \\
\hline Heart rate & 7 & 130 & 15 & $72-196$ \\
\hline Respiratory rate & 7 & 36 & 4.7 & $60-20$ \\
\hline $\mathrm{SpO}_{2}$ & 1 & 91 & 0.9 & $90-92$ \\
\hline
\end{tabular}

to prevent hypothermia by using hot water bottles, the temperature decreased under desirable levels in most cases. Fournier-Chambrillon et al (2003) described a decrease in temperature as the major adverse effect using KET-MED, but placing the animals on a warmed table was an effective way to correct this problem. This situation occurred in both species in our study. Quick reversal with ATI seems to be a key factor to control this adverse effect. However, the ideal would be to increase the temperature to normal ranges and then reverse it, but our field conditions with no access to electricity prevented this scenario.

For the KET-MED combination, cardiac rate in otters was below expected when compared to the previously reported heart rates (100-180 beats/min) for L. canadensis under inhalation anaesthesia with isofluorane (Spelman et al 1993). Some individuals had mild bradycardia with stable heartbeat, other individuals had a mild tendency to decrease cardiac rate, with an average of 86 beats/min. 

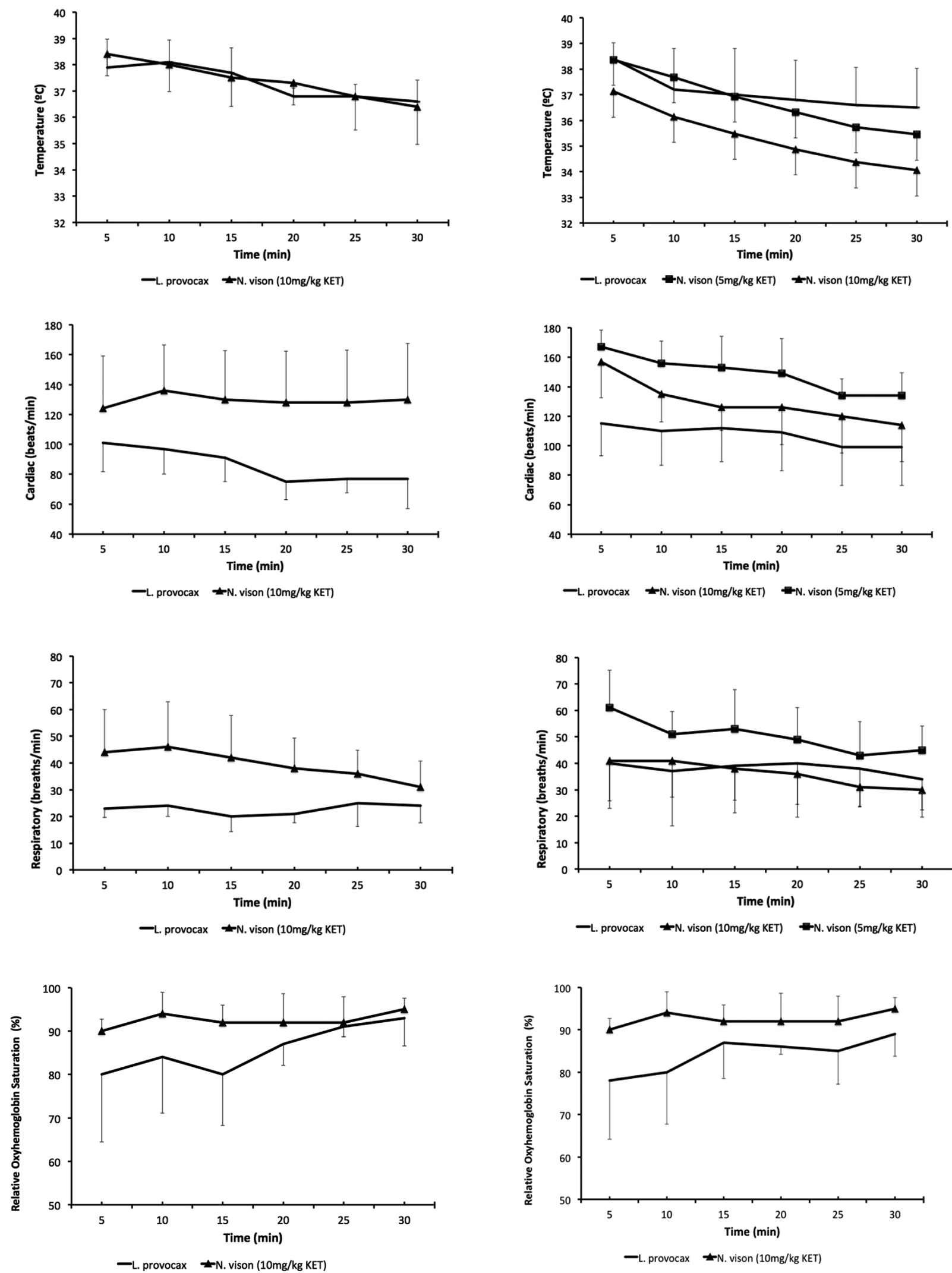

Figure 1. Means and SD (standard deviation) for rectal temperature, cardiac rate, respiratory rate and relative oxyhaemoglobin saturation at 5 min intervals for otters (L. provocax) and minks (N. vison) anesthetised with Ketamine-medetomidine (first column) and with Ketamine-dexmedetomidine (second column), the latter combination in two different doses of Ketamine in the case of minks. Single line: L. provocax; line with square: $N$. vison $5 \mathrm{mg} / \mathrm{kg} \mathrm{KET}$; line with triangle: $N$. vison $10 \mathrm{mg} / \mathrm{kg} \mathrm{KET}$. 
Heart rate in minks averaged 130 beats/min and there was a pattern of maintenance of cardiac activity with a small range of variation. However, four minks had some cardiac frequencies below the expected range. With the KET-DEX protocol only one otter had values of cardiac rate below 100 beats/min, with an average of 107 beats/min in otters, 149 beats/min in minks with LDK and 130 beats/min in minks with HDK. The cardiac rate was generally stable for all animals under both anaesthetic protocols, with a slight tendency to decrease, however, animals under KET-DEX had values closer to the expected, according to previously reported values (figure 1).

Respiratory rate for the KET-MED combination averaged 22 breaths/min in otters, within the expected normal range. Minks had a mean of 39 breaths/min and seven individuals presented pronounced tachypnea at the beginning of the procedure. With the KET-DEX combination, three otters and seven minks had pronounced tachypnea at the beginning of anaesthesia: the otters presented 64-68 breaths/min, and the minks had 44-60 breaths/min. In both species, respiratory rate stabilised in the second or third monitoring period, which subsequently decreased to normal values in all cases (figure 1). Respiratory rate under both protocols showed to be fairly stable, starting with tachypnea in some cases but tending to decrease to normal parameters. Respiratory rate may be higher using KET-DEX than KET-MED, possibly due to fewer adverse effects of DEX on the respiratory system.

The average values for $\mathrm{SpO} 2$ were above $80 \%$. Two otters under KET-MED and two otters under KET-DEX anaesthesia showed lower $\mathrm{SpO} 2$ values at the beginning of the anaesthetic procedure, possibly due to artefact movements and imprecise measurements during the monitor's adjustment on the tongue. Nevertheless, it is recommended to supplement oxygen if $\mathrm{SpO} 2$ drops below $90 \%$ when possible (figure 1 ).

Several adverse effects have been described using KET alone, especially hyperthermia, rigidity and convulsion (Reuther and Brandes 1984). Alternatively, a protocol with butorphanol/midazolam/medetomidine works well in seals and sea lions (Spelman 2004). In this study, the five anaesthetic combinations with KET-MED and KET-DEX lead to a rapid induction and complete inmobilisation with the advantage of being reversed with ATI. However, at low doses of KET, anaesthesia was not as deep as desirable at the beginning and at the end of the procedure. Doses $<5 \mathrm{mg} / \mathrm{kg}$ of KET may not induce reliable immobilisation. Arnemo et al (1994) recommended doses of KET between 6.5 and $11.8 \mathrm{mg} / \mathrm{kg}$, especially for painful procedures. Anaesthesia depth scores demonstrated that these two anaesthetic combinations can be used for short procedures, but supplementary anaesthesia is necessary for more complex procedures such as surgeries. Both anaesthetic combinations worked well. In the KET-MED combination, we used $2 \mathrm{mg} / \mathrm{kg}$ more KET than Bauquier et al (2010), because they used a low level of anaesthesia and in two cases they had to administer additional doses of ketamine. Taking all results together, we recommend the use of $8.0 \mathrm{mg} / \mathrm{kg}$ of KET and $0.025 \mathrm{mg} / \mathrm{kg}$ of DEX IM in otters, and $10 \mathrm{mg} / \mathrm{kg}$ of KET and $0.025 \mathrm{mg} / \mathrm{kg}$ of DEX IM in minks for field anaesthesia of short procedures $(<30 \mathrm{~min})$ with reversal by ATI $0.5 \mathrm{mg} / \mathrm{kg}$ IM.

\section{ACKNOWLEDGEMENTS}

Funding was provided by the Chilean Fund for Science and Technology (Fondecyt) project 1100139. The authors would also like to thank René Monsalve, Marcelo Fuentes-Hurtado and Sergio Navarrete for their help during campaigns in the field.

\section{REFERENCES}

Arnemo JM, Moe R, Søli NE. 1994. Immobilization of captive pine martens (Martes martes) with medetomidine-ketamine and reversal with atipamezole. J Zoo Wildl Med 25, 548-554.

Bauquier SH, Hinshaw KC, Ialeggio DM, Montgomery CL, Perkowski SZ. 2010. Reversible immobilization of giant otters (Pteronura brasiliensis) using medetomidine-ketamine and atipamezole. J Zoo Wildl Med 41, 346-349.

Fernandez-Moran J, Perez E, Sanmartin M, Saavedra D, MantecaVilanova X. 2001. Reversible immobilization of Eurasian otters with a combination of ketamine and medetomidine. $J$ Wildl Dis 37, 561-565.

Fiorello CV, Rapoport GS, Rivera S, Clauss TM, Brainard BM. 2014. Comparison of anesthesia with fully reversible dexmedetomidinebutorphanol-midazolam versus ketamine-midazolam in captive Asian small- clawed otters (Aonyx cinereus). J Am Vet Assoc 244, 107-114.

Fournier-Chambrillon C, Chusseau JP, Dupuch J, Maizeret C, Fournier P. 2003. Immobilization of free-ranging European mink (Mustela lutreola) and polecat (Mustela putorius) with ketamine-medetomidine and rever- sal by atipamezole. J Wildl Dis 39, 393-399.

Jalanka HH, Roeken BO. 1990. The use of medetomidine, medetomidineketamine combinations, and atipamezole in nondomestic mammals: a review. J Zoo Wildl Med 21, 259-282.

Larivière S. 1999. Lontra provocax. Mammalian Species 610, 1-4.

Matsukawa T, Sessler DI, Sessler AM, Schrieder M, Ozaki M, et al. 1995. Heat flow and distribution during induction of general anesthesia. Anesthesiology 82, 662-673.

Medina G. 1997. A comparison of the diet and distribution of southern river otter (Lutra provocax) and mink (Mustela vison) in Southern Chile. J Zool 242, 291-297.

Reuther CV, Brandes B. 1984. Über das auf- treten von hyperthermia bei der immobilisation von Europaïschen fischottern (Lutra lutra) mit ketaminhydrochlorid. Dtsch. Tieraerztl. Wochenschr 91, 6-68.

Spelman L, Sumner P, Levine J, Stoskopf M. 1993. Field anesthesia in the North American river otter (Lutra canadensis). J Zoo Wildlife Med 24, 19-27.

Spelman LH, Sumner PW, Levine JF, Stoskopf MK. 1994. Anesthesia of North American river otter (Lutra canadensis) with medetomidineketamine and reversal by atipamezole. J Zoo Wildl Med 25, 214-223.

Spelman LH. 1999. Otter anesthesia. In: Fowler ME, RE Miller (eds). Zoo \& Wild Animal Medicine: Current Therapy 4. W.B. Saunders Co., Philadelphia, USA, Pp 436-443.

Spelman LH. 2004. Reversible anesthesia of captive California sea lions (Zalophus californianus) with medetomidine, midazolam, butorphanol, and isoflurane. J Zoo Wildl Med 35, 65-69.

Soto-Azat C, Boher F, Flores G, Mora E, Santibanez A, et al. 2006. Reversible anesthesia in wild marine otters (Lontra felina) using ketamine and medetomidine. J Zoo Wildl Med 37, 535-538.

Taguchi A, Kurz A 2005. Thermal management of the patient: where does the patient lose and/or gain temperature? Curr Opin Anaesthesiol $18,632-639$. 
